\title{
A prospective study of management of subtrochanteric femur fracture using proximal femoral nail
}

\author{
Shwetabh Malik, Parimal Malviya*, Alfven Vieira, Deepak Jain
}

Department of Orthopaedics, MGM Institute of Health Sciences, Navi Mumbai, Maharashtra, India

Received: 11 November 2019

Revised: 2 February 2020

Accepted: 4 February 2020

\author{
*Correspondence: \\ Dr. Parimal Malviya, \\ E-mail: dr.parimal190@gmail.com
}

Copyright: (c) the author(s), publisher and licensee Medip Academy. This is an open-access article distributed under the terms of the Creative Commons Attribution Non-Commercial License, which permits unrestricted non-commercial use, distribution, and reproduction in any medium, provided the original work is properly cited.

\begin{abstract}
Background: Proximal femur fractures present considerable challenge in management. They are due to high velocity trauma, with or without soft tissue injury and usually with a metaphyseal and diaphyseal involvement. The surgeon has to face many challenges like identifying the entry, reduction the fracture, and difficulty due to a narrow medullary canal and comminution. The present study was conducted to assess the utility and effectiveness of Proximal Femoral Nail for subtrochanteric fractures of femur.

Methods: In this study a total of 30 patients with Sub trochanteric femur fracture admitted to MGM medical college and hospital from June 2015 to July 2017 were selected for treatment with proximal femur nail.

Results: 30 patients were included in this study with subtrochanteric fractures of femur treated with Proximal femoral nail. Maximum 21(70\%) of patients were below $61 \mathrm{yrs}$ of age. Mean age was 47.9 years. There was 21 male and 9 females in the study. There were 6 patients with local complications. Final result of our study, we had $26.7 \%$ excellent, $46.6 \%$ good, $20 \%$ fair and $6.7 \%$ poor results according to Harris hip score.

Conclusions: In our study, looking at the results we found that Proximal femoral Nail proves to be a good implant in management of subtrochanteric fractures of femur. However, it is a small study to conclude anything definitely.
\end{abstract}

Keywords: Subtrochanteric, Femur, Proximal femoral nail

\section{INTRODUCTION}

Proximal femur fractures present considerable challenge in management. They are due to high velocity trauma, with or without soft tissue injury and usually with a metaphyseal and diaphyseal involvement. The surgeon has to face many challenges like identifying the entry, reduction the fracture, and difficulty due to a narrow medullary canal and comminution. Subtrochanteric fractures of femur are different from intracapsular fractures when it comes to structural anatomy and biomechanical characteristics. ${ }^{1}$ Although these fractures are most difficult to manage in the femur, our improved understanding of the complex biology and biomechanics of the trochanteric region as well as the fast development of orthopaedic philosophy and implants has led to consensus on the treatment of trochanteric fractures. ${ }^{2}$ Among the femoral shaft injuries proximal femoral fractures present a peculiar problem of securing effective neutralization of deforming forces. The body weight and hip muscles result in bending movements and compressive forces that leads to malunion and non-union of the fracture and mechanical failure of the implants. ${ }^{3}$

However, the appropriate implant for the internal fixation of Subtrochanteric fractures is still debatable; and various different intra and extramedullary devices for their surgical fixation have been advocated. ${ }^{4}$ Various hospitals have used proximal femoral devices like dynamic condylar screw, dynamic hip screw with barrel plate, 
gamma nail, proximal femoral nail etc., and claims to achieve reasonably satisfactory results with each type of device. The present study was conducted to assess the utility and effectiveness of Proximal Femoral Nail for subtrochanteric fractures of femur.

\section{METHODS}

In this study a total of 30 patients with Sub trochanteric femur fracture admitted to MGM medical college and hospital from June 2015 to July 2017 were selected for treatment with proximal femur nail.

\section{Statistical analysis}

The data was presented using frequency, percentage and mean, followed by graphs and charts. Further statistical analysis was performed using Chi-square test for significance of proportion; the level of significance was set at $5 \%$. All $\mathrm{p}$ values less than 0.05 were treated as significant.

\section{Primary treatment}

The patients were examined thoroughly for vital signs, head injury, thoraco-abdominal injury and other associated injuries. The distal circulation was checked and the limb was examined for any neurological deficit.

\section{Diagnostic radiology}

Standard antero-posterior and lateral views of the affected hip were obtained for diagnosis, extent of comminution and to measure likely length of implant. Temporary immobilization was given in form of Thomas splint. All routine blood investigations and medical and preoperative aesthetic check-ups were carried out as necessary for surgery.

\section{Preoperative investigation and planning}

Patients with no associated injury were operated in routine operation theatre as soon as the fitness of the patient for anaesthesia was obtained.

\section{Anaesthesia}

All surgeries were performed under regional anaesthesia except in cases with head injury in which general anaesthesia was given.

\section{Patient positioning}

The patients are positioned supine on the fracture table with a radiolucent padded counter-traction post placed between the patient's leg. The uninjured leg is held in wide abduction by a boot attached to one of the leg extensions of the fracture table. The injured leg is held in slight adduction, by a boot attached to the other leg extension of the fracture table. The C-arm image intensifier is positioned between the patient's legs and the adequacy of both the antero-posterior and lateral views are verified, before surgical preparation.

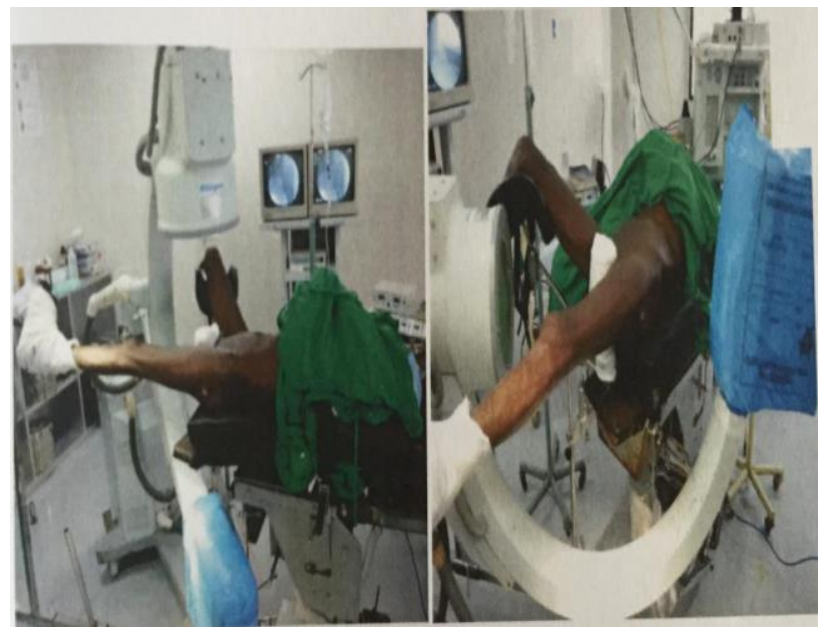

Figure 1: Patient positioning.

\section{Reduction technique}

After the anaesthetized patient is positioned on the fracture table, and the extremity is secured in the traction foot piece, traction is exerted longitudinally on the slightly abducted injured leg until reduction is achieved. The degree of rotation required for rotation is variable, depending on the degree of comminution. In noncomminuted fractures without displacement, the limb was fixed in neutral or slight internal rotation. In comminuted fractures, 15 to 20 degrees of external rotation is required to close the defect postero-laterally. Reduction is checked in the antero-posterior and lateral views in an image intensifier.

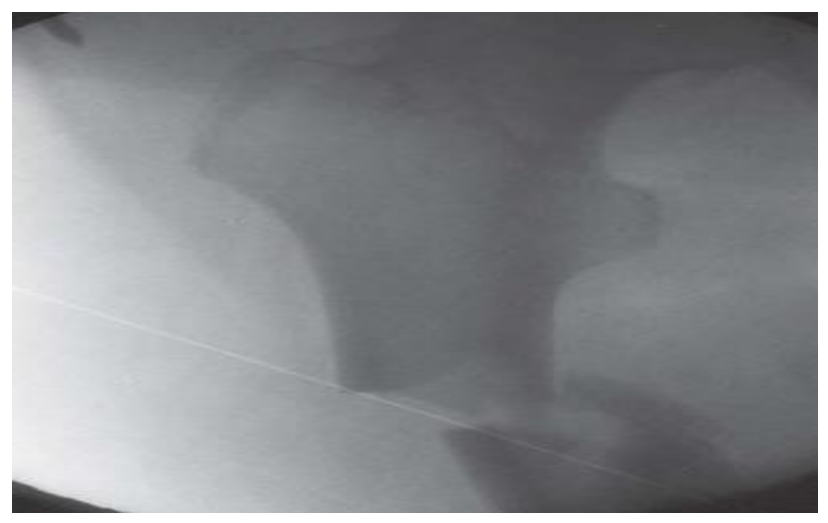

Figure 2: Pre-op X-ray.

\section{Draping}

The skin over the hip is scrubbed with betadine scrub, for 10 minutes and painted with betadine $10 \%$ and spirit. The lateral aspect of the hip is squared off from the iliac crest to the knee, with towels and drapes. A plastic transparent, adherent, isolation drape is directly applied to the skin at the proposed incision site. 


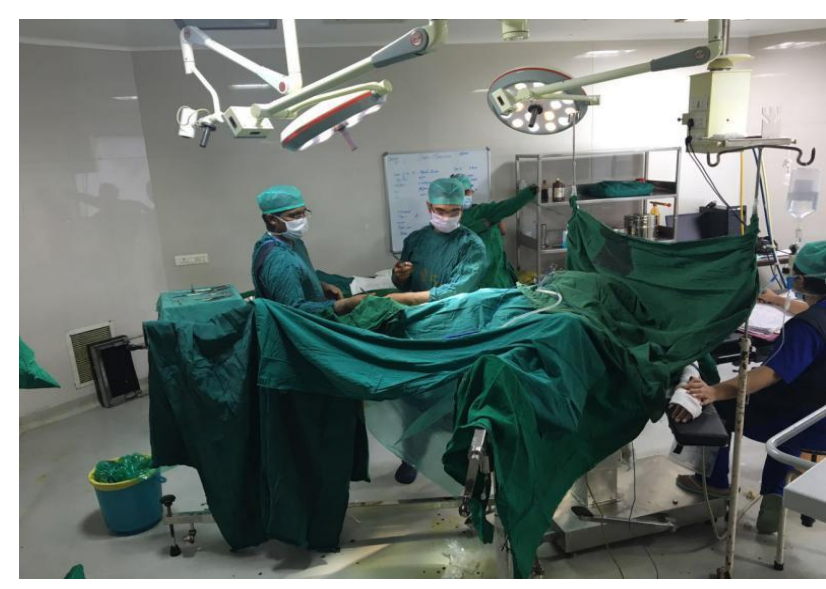

Figure 3: Draping.

\section{RESULTS}

In this study a total of 30 patients with Subtrochanteric femur fracture admitted to MGM medical college and hospital from June 2015 to July 2017 were selected for treatment with proximal femur nail. Maximum 21 (70\%) of patients were below 61yrs of age, mean age was 47.9 years.

There was a male predominance in the study with males being $21(70 \%)$ of the study group and females were 9 (30\%). $17(56.7 \%)$ patients had fractures due to vehicular accidents and $13(43.3 \%)$ patients had fracture due to trivial fall. $18(60 \%)$ patients had fractures of right side and $12(40 \%)$ patients had fractures of left side. $22(73 \%)$ patients were operated within a period of 1-2 hours with only 2 patients requiring more than 2 hours of operative time. Mean operative time was 75.3 mins. 2 (6.7\%) patients had blood loss of less than $50 \mathrm{ml}$ during the operation and $17(56.6 \%)$ patients had a blood loss of 50$100 \mathrm{ml}$ and $11(36.7 \%)$ patients had a blood loss of 100$200 \mathrm{ml}$. Mean blood loss was $117 \mathrm{ml} .14(46.6 \%)$ patients were discharged within 1-5 days post operatively 8 (26.7\%) patients were discharged within 6-10 days and rest $8(26.7 \%)$ patients were discharged in 11-20 days post op . Mean hospital stay of patients was 8.6 days. The mean time for partial weight bearing was 7.6 weeks post op. The mean time for full weight bearing was 10.93 weeks. The mean time for radiological union was 7.6 weeks post op. There were 6 patients with local complications. Final result of our study, we had $26.7 \%$ excellent, $46.6 \%$ good, $20 \%$ fair and $6.7 \%$ poor results according to Harris hip score.

Table 1: Age distribution of patients.

\begin{tabular}{|lll|}
\hline Age (years) & Number & Percentage (\%) \\
\hline Below 30 & 7 & 23.4 \\
\hline $\mathbf{3 1 - 4 0}$ & 5 & 16.6 \\
\hline $\mathbf{4 1 - 5 0}$ & 6 & 20 \\
\hline $\mathbf{5 1 - 6 0}$ & 3 & 10 \\
\hline Above 61 & 9 & 30 \\
\hline
\end{tabular}

Table 2: Sex distribution.

\begin{tabular}{|lll|}
\hline Sex & Number & Percentage (\%) \\
\hline Male & 21 & 70 \\
\hline Female & 09 & 30 \\
\hline Total & 30 & 100 \\
\hline
\end{tabular}

Table 3: Operative time of procedure.

\begin{tabular}{|lll|}
\hline $\begin{array}{l}\text { Time of } \\
\text { procedure (hrs) }\end{array}$ & Number & Percentage (\%) \\
\hline $\mathbf{0 - 1}$ or less & 6 & 20 \\
\hline $\mathbf{1 - 2}$ & 22 & 73 \\
\hline $\mathbf{2 . 1 - 3}$ & 02 & 6.6 \\
\hline Total & 30 & 100 \\
\hline
\end{tabular}

Table 4: Starting of partial weight bearing.

\begin{tabular}{|lll|}
\hline Weeks & Number & Percentage (\%) \\
\hline Within 1 & 0 & 0 \\
\hline 01 to 06 & 9 & 30 \\
\hline 07 to 10 & 20 & 66.7 \\
\hline 11 -above & 1 & 3.3 \\
\hline Total & 30 & 100 \\
\hline
\end{tabular}

Table 5: Starting of full weight bearing.

\begin{tabular}{|lll|}
\hline Weeks & Number & Percentage $(\%)$ \\
\hline 0 to 06 & 0 & 0 \\
\hline $\mathbf{0 7}$ to 12 & 23 & 76.7 \\
\hline $\mathbf{1 3}$ to 18 & 7 & 23.3 \\
\hline$>\mathbf{1 8}$ & 0 & 0 \\
\hline Total & 30 & 100 \\
\hline
\end{tabular}

Table 6: Time of radiological union.

\begin{tabular}{|lll|}
\hline $\begin{array}{l}\text { Time of } \\
\text { radiological union }\end{array}$ & Number & Percentage (\%) \\
\hline 1-6 weeks & 9 & 30 \\
\hline 7-12 weeks & 21 & 70 \\
\hline 13-18 weeks & 0 & 0 \\
\hline Total & 30 & 100 \\
\hline
\end{tabular}

Table 7: Functional results (according to Harris hip score).

\begin{tabular}{|llll|}
\hline $\begin{array}{l}\text { Clinical } \\
\text { results }\end{array}$ & Points & Number & Percentage (\%) \\
\hline Excellent & $90-100$ & 8 & 26.7 \\
\hline Good & $80-89$ & 14 & 46.6 \\
\hline Fair & $70-79$ & 6 & 20 \\
\hline Poor & $<70$ & 2 & 6.7 \\
\hline Total & & 30 & 100 \\
\hline
\end{tabular}




\section{DISCUSSION}

Fractures of the long bones are a major social and economic problem. Of the long bone fractures Subtrochanteric fractures of the femur have peculiar anatomic and mechanical characteristics which poses problems in their management. Closed intramedullary devices have a mechanical advantage that effectively addresses these factors. The benefit of minimal surgical exposure, more efficient load transfer through calcar femoral and decreased tensile strain on the implant because of its shorter lever arm makes proximal Femoral Nail a good choice of implant for subtrochanteric fractures of the femur. Various studies have considered proximal femoral nail as an acceptable minimally invasive implant for Subtrochanteric fracture.

In this study an attempt was made to survey, evaluate, document and quantify our success in the management of such individuals by using proximal femoral nail implants and evaluate the result with the results of three other studies by Boldin et al in 2003, El-Mowa et al in 2013 and Abraham et al in 2016. ${ }^{5-7}$

21 of the patients in our study were males. In all other studies also, there is a male preponderance. Most common cause of injury in all studies is vehicular accident followed by fall. Mean operative time of procedure in our study was 75.3 minutes which was well comparable to other study which is 68 mins in study by Boldin et al and 100 min in El-Mowa et al..$^{5,6}$ Duration of hospitalization is between 6 and 10 days of postoperative period. In our study its 8.6 days. In our study, the mean time for partial weight bearing was 7.6 weeks. In a study of 55 cases by Boldin et al, mean time for partial weight bearing was 6 weeks. In a study of 20 cases by El-Mowa et al, mean time for partial weight bearing was 5.8 weeks. ${ }^{6}$ In all studies full weight bearing walking was started between 1.5 and 2 months. In our study it is mean 10.93 weeks. Complications were superficial and deep infection, screw breakout. In our study, 6 cases of PFN group were associated with complications. In a study of 20 cases by El-Mowa et al, five complications were observed during the follow-up of four months. ${ }^{6} 3$ patients had implant backout. 1 patient had deep infection for which debridement was done and 1 patient had superficial infection which was managed by antibiotics. In our study, 8 cases $(26.7 \%)$ had excellent results, 14 cases $(46.6 \%)$ had good results, 6 cases $(20 \%)$ had fair results and 2 case $(6.7 \%)$ had poor result. In a study of 55 cases by Boldin et al, Postoperative radiographs showed near anatomic fracture reduction in 34 patients. ${ }^{5}$ The fracture healed in all 55 patients. The longest consolidation time was 5 , months. In a study of 20 cases by El-Mowa et al, 5 patients had excellent results, 8 scored good results, 4 scored moderate and 3 scored poor results. ${ }^{6}$ In a study of 30 patients by Abraham et al had very good result, 9 had good results and 4 patients had moderate results and 3 had poor results. ${ }^{7}$

\section{CONCLUSION}

In our study, looking at the results we found that patients treated with proximal femoral nail had good outcomes in terms of short operative time, less intraoperative blood loss, short duration of hospitalization, early mobilization in terms of partial and full weight bearing, less complications and good functional outcome on the basis of Harris hip score at final follow up. Thus, from our study proximal femoral nail proves to be a good implant in management of subtrochanteric fractures of femur. However, it is a small study to conclude anything definitely.

\section{Funding: No funding sources}

Conflict of interest: None declared

Ethical approval: The study was approved by the institutional ethics committee

\section{REFERENCES}

1. Lavelle DG. Fractures and dislocations chapter-52 in Campbells operative Orthopaedics, tenth edition. 3;2897-2908.

2. Jiang LS, Shen L, Dai LY. Intramedullary Fixation of Subtrochanteric Fractures with Long Proximal Femoral Nail or Long Gamma Nail. Tech Notes Prelim Results. 2007;36:10.

3. Broos PL, Reynders P. The use of the unreamed AO femoral intramedullary nail with spiral blade in nonpathological fractures of the femur: experiences with eighty consecutive cases. J Orthop Trauma 2002;16:150-4.

4. Blatter G, Janssen M. Treatment of subtrochanteric fractures of the femur: reduction on the traction table and fixation with dynamic condylar screw. Arch Orthop Trauma Surge. 1994;113:138-41.

5. Boldin C, Seibert FJ, Fankhauser F, Peicha G, Grechenig W, Szyszkowitz R. The proximal femoral nail (PFN) - a minimal invasive treatment of unstable proximal femoral fractures: A prospective study of 55 patients with a follow-up of 15 months; 2009: 53-58.

6. El-Mowa HM, Eid TA, El-Sayed AS, Zalalo SH. fixation of subtrochanteric fracture using proximal femoral nail. Menoufia Medical J. 2014;27:208-14.

7. Abraham VT, Chandrasekaran M, Mahapatra S. Outcome of subtrochanteric fracture of the femur managed with proximal femoral nail. Int Surge J. 2016;3(3):1296-300.

Cite this article as: Malik S, Malviya $\mathrm{P}$, Vieira A, Jain D. A prospective study of management of subtrochanteric femur fracture using proximal femoral nail. Int J Res Orthop 2020;6:292-5. 